\title{
A Test of the Equal-Environment Assumption In Twin Studies of Psychiatric Illness
}

\author{
Kenneth S. Kendler, ${ }^{1,2,5}$ Michael C. Neale, ${ }^{2}$ Ronald C. Kessler, ${ }^{3}$ Andrew C. Heath, ${ }^{4}$ and \\ Lindon J. Eaves ${ }^{1,2}$
}

Received 30 April 1992-Final 3 June 1992

\begin{abstract}
The traditional twin method is predicated on the equal-environment assumption (EEA)-that monozygotic (MZ) and dizygotic (DZ) twins are equally correlated in their exposure to environmental events of etiologic importance for the trait under study. In 1968, Scarr proposed a test of the EEA which examines the impact of phenotypic similarity in twins of perceived versus true zygosity. We apply this test for the EEA to five common psychiatric disorders (major depression, generalized anxiety disorder, phobia, bulimia, and alcoholism), as assessed by personal interview, in 1030 female-female twin pairs from the Virginia Twin Registry with known zygosity. We use a newly developed modelfitting approach which treats perceived zygosity as a form of specified familial environment. In 158 of the 1030 pairs $(15.3 \%$ ), one or both twins disagreed with the projectassigned zygosity. Model fitting provided no evidence for a significant influence of perceived zygosity on twin resemblance for any of the five disorders. Although limited in power, these results support the validity of the EEA in twin studies of psychiatric disorders.
\end{abstract}

KEY WORDS: Twin studies; equal-environment assumption; psychiatric disorders; depression; alcoholism; anxiety disorders.

\section{INTRODUCTION}

The traditional twin method, as well as more recent biometrical models for twin analysis, are predicated on the equal-environment assumption (EEA) - that monozygotic (MZ) and dizygotic (DZ) twins are equally correlated for their exposure to environmental influences that are of etiologic relevance to the trait under study. If the EEA is not correct, then the excess resemblance of $\mathrm{MZ}$ over $\mathrm{DZ}$ twins, which is usually attributed

\footnotetext{
${ }^{1}$ Department of Psychiatry, Medical College of Virginia/Virginia Commonwealth University, Richmond, Virginia 23298.

2 Department of Human Genetics, Medical College of Virginia/Virginia Commonwealth University, Richmond, Virginia 23298.

3 Institute for Social Research, University of Michigan, Ann Arbor, Michign 48109.

${ }^{4}$ Department of Psychiatry, Washington University School of Medicine, St. Louis, Missouri 63130.

5 To whom correspondence should be addressed at Box 710 MCV Station, Richmond, Virginia 23298-0710.
}

to genetic factors, could in part be explained by environmental effects.

Four major methods have been designed to test the validity of the EEA in twin studies (Kendler, 1983). The first method to test the EEA assumes that resemblance in twins is influenced by the similarity of their treatment by the social environment, which in turn reflects their degree of physical resemblance. If this is the case, then, controlling for zygosity, physical similarity of twin pairs should correlate with trait similarity. We are aware of three studies using this method, two examining the normative traits of intelligence and personality (Plomin et al., 1976; Matheny et al., 1976) and one examing schizophrenia (Kendler, 1983). None of these studies suggested that twin resemblance was substantially influenced by physical similarity.

The second method involves direct observation of twins in a social or family setting in which the behavior of other individuals is divided into 
those which are self-initiated and those which occur in response to behavior of the twins. In the one application of this method known to us, Lytton (1977) studied very young twins and their parents and found that the excess resemblance in the parental treatment of $\mathrm{MZ}$ vs. $\mathrm{DZ}$ twins was entirely attributable to parental behavior which was in response to twin behavior.

The third method rests on observations that certain measurable features of the childhood and adult environments of $\mathrm{MZ}$ twins are more similar than for DZ twins. For example, MZ twins report that they more frequently shared playmates, shared the same room, and were dressed alike as children than same-sex DZ twins (Loehlin and Nichols, 1976; Kendler et al., 1986, 1992c). Furthermore, as adults $\mathrm{MZ}$ twins are in more frequent contact than samesex DZ twins and more frequently cohabit (Kendler et al., 1986, 1992c; Rose et al., 1990). If these environmental experiences influence twin similarity, then this might represent a violation of the EEA and should be detectable by correlating, separately within each zygosity group, the degree of resemblance to the degree of similarity of environment in childhood or adulthood. Loehlin and Nichols (1976) were unable to find significant correlations between childhood environmental similarity and similarity for personality or intellectual ability in adolescents. Kendler and colleagues were unable to find any consistent relationship between childhood or adult environmental similarity and twin resemblance for self-report symptoms of anxiety and depression (Kendler et al., 1986) or clinically diagnosed major depression (Kendler et al., 1992c), phobia (Kendler et al., 1992a), generalized anxiety disorder (Kendler et al., 1992b), or alcoholism (Kendler et al., 1992d). A similar pattern of results has been reported for personality and symptoms of anxiety and depression (Morris-Yates et al., 1990), social attitudes (Martin et al., 1986), and alcohol consumption (Heath et al., 1989). In contrast, Clifford et al. (1984) found that the similarity of adult environment did influence self-report psychiatric symptoms and Kaprio et al., (1990) found the same pattern of effects on alcohol intake and personality. The limitation of this method, as Lykken et al. (1990) have pointed out, is that a correlation between frequency of adult contact and phenotypic similarity in twin pairs need not be a causal one. Degree of phenotypic similarity could also influence frequency of contact.

The fourth method, initially proposed by Scarr
(1968), involves a comparison of trait similarity in twins as a function of both "real" zygosity, as assessed by the investigators, and "perceived" zygosity, as reported by the twins or their parents. If their families, their social environment, or the twins themselves expect $\mathrm{MZ}$ twins to be more similar than DZ twins, and this expectation influences trait similarity in the twins, then perceived zygosity should influence twin similarity. This method for testing the EEA has one distinct advantage over the preceding approaches. While all three previous methods require the investigator to assess only one potential source of trait similarity in twins (physical appearance, dressing alike as children, actions of parent in a lab situation, etc.), this method provides a global test for all potential environmental influences that are dependent on zygosity associated attitudes and expectations. Studies using this method, which requires that a certain proportion of twins be misinformed about their zygosity, have examined traits such as intelligence, attitudes, hyperactivity, and personality and have found little evidence that perceived zygosity influences twin resemblance (Scarr, 1968; Munsinger and Douglass, 1976; Matheny, 1979; Scarr and Carter-Saltzman, 1979; Goodman and Stevenson, 1989).

In this report, we apply, for the first time to our knowledge, an assessment of the impact of perceived zygosity on twin resemblance for psychiatric disorders as diagnosed by personal structured psychiatric interview in a large population-based sample of female-female twin pairs.

\section{METHODS}

\section{Sample and Diagnostic Methods}

As detailed elsewhere (Kendler et al., 1992c), as part of a longitudinal study of the genetic and environmental risk factors for common psychiatric disorders in women, we personally interviewed 2163 female twins from the population-based Virginia Twin Register, where both members had previously returned mailed questionnaires. This sample included both members of 1033 pairs and 97 individual twins, whose mean age $( \pm S D)$ was $30.1+$ 7.6. The refusal rate during the personal interview phase of this project was $8 \%$. All twins were interviewed by an individual with a master's degree in social work and/or at least 2 years' clinical experience, blind to the psychopathologic status of the cotwin. Eighty-nine percent of the interviews 
were conducted face to face, usually in the twin's residence, and $11 \%$ by phone.

The interview included, in modified form, sections of the Structured Clinical Interview for DSMIII-R (Sptizer et al., 1987) for major depression, generalized anxiety disorder, bulimia nervosa, and alcohol dependence. Phobias were assessed by an adaption of the Phobic Disorders section of the Diagnostic Interview Schedule (DIS) Version III-A (Robins and Helzer, 1985), which in turn was based on the DSM-III criteria (American Psychiatric Association, 1980). The diagnoses of major depression, bulimia and generalized anxiety disorder were based on a blind review by K.S.K., using DSMIII-R criteria (American Psychiatric Association, 1987), of the interview protocols. Because of the relative rarity of bulimia, in the analyses of this diagnosis only, we included "possible" cases that appeared to be clinically affected but did not meet full diagnostic criteria (Kendler et al., 1991). We have previously shown that from both an epidemiologic and a genetic perspective, possible and definite cases of bulimia appear to share all the same risk factors (Kendler et al., 1991). Phobia was defined as the presence of 1 of 17 specific fears which the respondent considered to be irrational and which, in the interviewer's judgment, produced objective behavioral interference with the respondent's life. To maximize our statistical power for the study of "alcoholism," we chose the broad criteria of alcohol dependence as defined by DSM-IIIR (American Psychiatric Association, 1987) or "problem drinking," in which the respondent admits to having had, or being considered by others as having, a significant "drinking" problem not limited to single isolated incidents. A multiplethreshold model indicates that in these data, problem drinking reflects a milder disturbance on the same liability dimension that influences alcohol dependence (Kendler et al., 1992d). We have reanalyzed the data using the standard DSM-III-R definition of alcohol dependence, and they do not differ qualitatively from those reported here.

\section{Zygosity Determination}

All zygosity information from the 1033 pairs where both members were interviewed was reviewed by two experienced twin researchers blind to information about their psychiatric status. Information reviewed included responses to questions about physical similarity, frequency of confusion as children by parents, teachers, and strangers, and whether, as children, the twin and her cotwin were as alike as "two peas in a pod" or only of "normal family likeness." Furthermore, in over $80 \%$ of the pairs, frontal photographs were available for both members. On the basis of this review, twin pairs were classified into five groups: definitely $M Z$, definitely $\mathrm{DZ}$, probably $\mathrm{MZ}$, probably $\mathrm{DZ}$, and zygosity uncertain. Disagreement between the two raters was resolved by consensus. We attempted to obtain blood samples from both members of the pairs in the final three categories and were successful in 119 of the 186 pairs so classified. Zygosity was determined by the examination of DNA polymorphisms, using 8 highly informative probes, which, if all identical, produced a probability of monozygosity of 0.9997 (Spence et al., 1988). Final zygosity determination, which used blood samples where available and a definite or probable zygosity diagnosis otherwise, yielded $590 \mathrm{MZ}$ twin pairs, 440 $\mathrm{DZ}$ twin pairs, and 3 pairs classified as uncertain. DNA methods validated our zygosity diagnosis in 87 of $105(83 \%)$ twin pairs in the "probable" category. DNA- or previously obtained blood groupbased zygosity diagnoses confirmed our assignment in 26 of 26 pairs in the "definite" category. In our analyses here, we focus on the 1030 twin pairs of known zygosity.

All twins were also asked whether, in their opinion, they were definitely identical, probably identical, probably fraternal, definitely fraternal, or not sure what kind of twin they were. We then asked them, "On what do you base your opinion?" to which the interviewers coded five non-mutually exclusive responses: (i) physical appearance, (ii) parents told at birth because of number of placentas, (iii) parents told at birth-other reasons or reasons unknown, (iv) told by doctor-no blood tests, and $(v)$ blood tests.

\section{Method of Analysis}

As outlined in Figure 1, one of us (MCN) has developed, using the software package Mx (Neale, 1991), a method of testing for the presence of violations of the EEA by including in the standard twin model a "specified" form of familial environment. In the present study, this specified environment was indexed by self-report zygosity and reflected the impact on twin similarity of the expectations of the twins themselves, their families, and their more extended social environment (e.g., 
teachers, friends). On this hypothetical scale of selfreport zygosity, we assigned twins who both considered themselves to be identical a score of 1.0 , pairs who both considered themselves to be fraternal a score of 0 , and all other pairs (e.g., twins who disagreed about their zygosity or where one or both members of the pair responded that they did not know their own zygosity) as 0.50 . The model for any given disorder was then fit directly to six $2 \times 2$ contingency tables cross-classifying the affection status of twin 1 and twin 2, three each for $\mathrm{MZ}$ and $\mathrm{DZ}$ twins, each divided into pairs with a score of $0,0.5$, and 1 on our scale of specified familial environment.

The full model for these analyses, as shown in Figure 1 , includes the standard estimates of $A$, additive genetic effects, and $E$, individual specific environment. In addition, estimates were available for the specified common or family environment $\left(C_{\mathrm{S}}\right)$ (i.e., the effect of perceived zygosity) and the remaining or residual common environment $\left(C_{R}\right)$.

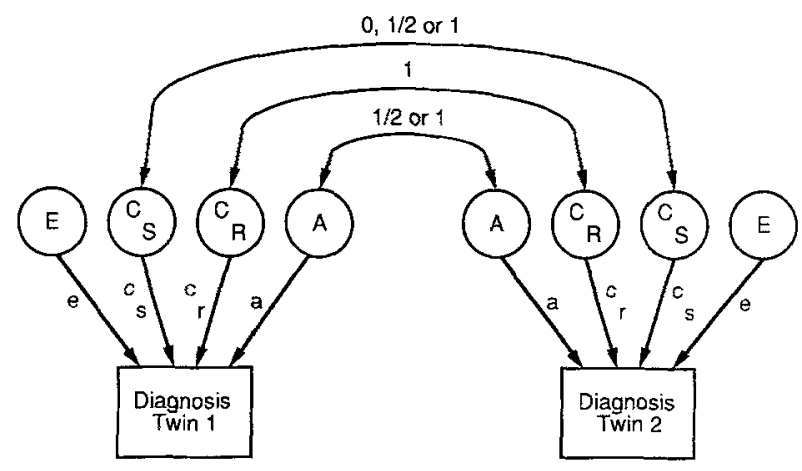

Fig. 1. A path diagram of the model used for analyzing the impact of perceived zygosity on twin resemblance for psychiatric disorders. Four sources of variation in liability to the diagnosed disorder are considered: additive genetic effects $(A)$, specified common or familial environment $\left(C_{\mathrm{S}}\right)$, residual common environment $\left(C_{\mathrm{R}}\right)$, and individual-specific environment $(E)$. The path coefficients associated with these sources of variation are, respectively, $a, c_{s}, c_{\mathrm{y}}$, and $e$. Specified family environment here reflects the effects of "perceived zygosity" - the expectations from the twins themselves, their families, and their social environment that twins considered to be $\mathrm{MZ}$ will be similar. This specified family environment is assumed to have a correlation of (i) unity in twins who agree that their zygosity is MZ, (ii) zero in twins who agree that their zygosity is $\mathrm{DZ}$, and (iii) one-half in those who disagree or are uncertain about their zygosity. Residual common environment is, by definition, assumed to be perfectly correlated in all twin pairs. Additive genetic effects are assumed to be perfectly correlated in $\mathrm{MZ}$ twins are correlated one-half in $\mathrm{DZ}$ twins.
The proportions of variance in liability due to these four sets of factors are termed $a^{2}, e^{2}, c_{\mathrm{s}}{ }^{2}$, and $c_{\mathrm{r}}{ }^{2}$, respectively. The model assumes that being considered MZ twins results in an excess twin similarity in liability by an amount equal to $c_{\mathrm{s}}{ }^{2}$. Disagreeing or being of uncertain zygosity contributes $1 / 2 c_{\mathrm{s}}^{2}$ to twin similarity. The model assumes that being considered a DZ twin makes no additional contribution to twin similarity. Since we have previously demonstrated that additive genetic effects were prominent for all these disorders (Kendler et al., 1991, 1992a-d), we considered two tests for the validity of the EEA. First, we compared the fit of the full or $A C_{\mathrm{S}} C_{\mathrm{R}} E$ model to that of the $\mathrm{AC}_{\mathrm{R}} \mathrm{E}$ model. Second, we compared the fit of the $\mathrm{AC}_{\mathrm{s}} \mathrm{E}$ model to that of the $A E$ model. The fit of these models was evaluated by Akaike's information criterion (AIC) (1987), which equals chi-square minus twice the degrees of freedom. The better the overall balance of goodness of fit and parsimony, the more negative is the AIC.

\section{RESULTS}

The relationship between the assigned zygosity and the self-report zygosity in the 1030 pairs of evaluated twins is shown in Table I. In 477 of the 590 twins $(80.9 \%$ ) classified as $\mathrm{MZ}$, both twins agreed that they were definitely or probably identical. In 395 of the $440(89.8 \%)$ twins classified as DZ, both twins agreed that they were definitely or probably fraternal. Of interest, while in $10.9 \%$ of the pairs classified as $\mathrm{MZ}$, both twins considered themselves fraternal, in only $0.7 \%$ of pairs classified as DZ, did both pairs consider themselves identical.

In the 2060 members of the complete twin pairs of known zygosity, the lifetime prevalence of the disorders considered here is as follows: major depression, 31.4\%; generalized anxiety disorder, 23.6\%; phobia, $30.5 \%$; bulimia, $5.7 \%$; and broadly

Table I. Perceived Versus Assigned Zygosity in 1030 Personally Evaluated Female-Female Twin Pairs

\begin{tabular}{lrrrrr}
\hline & \multicolumn{4}{c}{ Assigned zygosity } \\
\cline { 2 - 4 } \cline { 5 - 6 } & \multicolumn{2}{c}{$\mathrm{MZ}$} & & \multicolumn{2}{c}{$\mathrm{DZ}$} \\
\cline { 2 - 6 } \cline { 5 - 7 } Perceived zygosity & $N$ & $\%$ & & $N$ & $\%$ \\
\hline Agree identical & 477 & 80.9 & & 3 & 0.7 \\
Disagree on zygosity & 29 & 4.9 & & 17 & 3.9 \\
One or both & & & & \\
$\quad$ zygosity unknown & 20 & 3.4 & & 25 & 5.7 \\
Agree fraternal & 64 & 10.9 & 395 & 89.8 \\
\hline
\end{tabular}


defined "alcoholism," $17.3 \%$. The formal evaluations of the EEA assumption for these disorders are shown in Table II. For all disorders, the fit of the $A C_{\mathrm{R}} E$ model, as assessed by the $\mathrm{AIC}$, was superior to that of the full or $A C_{\mathrm{S}} C_{\mathrm{R}} E$ model. In fact, for all disorders except major depression, the deterioration in fit with setting $C_{\mathrm{s}}$ to zero was less than $0.05 \chi^{2}$ unit. A very similar pattern of results was obtained when comparing the fit of the $A C_{\mathrm{S}} E$ model to that of the $A E$ model. For all the disorders, the best fit by AIC was provided by the $A E$ model.

\section{DISCUSSION}

This report represents, to our knowledge, the first application to psychiatric disorders of a test for the EEA initially proposed by Scarr (1968) of comparing phenotypic similarity as a function of perceived versus "true" zygosity. In a population-based sample of female-female adult twin pairs, self-reported zygosity in both members of the twin pair agreed with assigned zygosity in about $85 \%$ of pairs. This is a somewhat higher rate than in most previous reports (Loehlin and
Nichols, 1976; Scarr, 1968; Scarr and CarterSaltzman, 1979; Matheny, 1979; Munsinger and Douglass, 1976). However, these studies examined younger twins and often asked the parents of the twins rather than the twins themselves. Adult twins may be more accurate in their assessment of their own zygosity than are twins in adolescence or childhood or their parents.

Consistent with some (Matheny, 1979; Lytton, 1977), but not other (Scarr, 1968; Munsinger and Douglass, 1976), reports the disagreements between self-reported and assigned zygosity were not symmetrical in this sample; many more $M Z$ twins considered themselves to be $\mathrm{DZ}$ than vice versa. In an attempt to understand this finding, we compared the reasons given for belief about zygosity in $\mathrm{MZ}$ twins where both considered themselves $\mathrm{DZ}$ vs. twins who were, in our judgment, both correct in considering themselves either $\mathrm{MZ}$ or $\mathrm{DZ}$ (Table III). Compared to either $\mathrm{MZ}$ or $\mathrm{DZ}$ twins who were correct about their zygosity, $M Z$ twins who believed that they were $\mathrm{DZ}$ were much less likely to base their opinion on physical appearance but more likely to base their opinion on what their parents were

Table II. Model-Fitting Results for Major Depression, Generalized Anxiety Disorder, Phobia, Bulimia, and Alcoholisn, Including Perceived Zygosity as a Form of Specified Family Environment ${ }^{a}$

\begin{tabular}{|c|c|c|c|c|c|c|}
\hline \multirow[b]{2}{*}{ Disorder } & \multicolumn{4}{|c|}{ Fit of the model ( $x^{2}$ units) } & \multicolumn{2}{|c|}{$\begin{array}{l}\text { Parameter } \\
\text { estimates } \\
\text { of best-fit } \\
\text { model by } \\
\text { AIC }\end{array}$} \\
\hline & $\begin{array}{l}A C_{\mathrm{s}} C_{\mathrm{R}} E \\
(\mathrm{df}=14)\end{array}$ & $\begin{array}{c}A C_{\mathrm{R}} E \\
(\mathrm{df}=15)\end{array}$ & $\begin{array}{c}A C_{\mathrm{S}} E \\
(\mathrm{df}=15)\end{array}$ & $\begin{array}{c}A E \\
(d f=16)\end{array}$ & $x^{2}$ & $e^{2}$ \\
\hline \multicolumn{7}{|l|}{ Major depression } \\
\hline $\begin{array}{l}x^{2} \\
\text { AIC }\end{array}$ & $\begin{array}{r}20.25 \\
-7.44\end{array}$ & $\begin{array}{r}22.42 \\
-7.59\end{array}$ & $\begin{array}{r}20.78 \\
-9.22\end{array}$ & $\begin{array}{c}22.42^{b} \\
-9.59\end{array}$ & 0.43 & 0.57 \\
\hline \multicolumn{7}{|c|}{$\begin{array}{l}\text { Generalized anxiety } \\
\text { disorder }\end{array}$} \\
\hline $\begin{array}{c}\chi^{2} \\
\text { AIC } \\
\text { Phobia }\end{array}$ & $\begin{array}{r}21.32 \\
-6.68\end{array}$ & $\begin{array}{r}21.32 \\
-8.68\end{array}$ & $\begin{array}{r}21.32 \\
-8.68\end{array}$ & $\begin{aligned} & 21.32^{b} \\
- & 10.68\end{aligned}$ & 0.34 & 0.66 \\
\hline $\begin{array}{c}\chi^{2} \\
\text { AlC } \\
\text { Bulimia }\end{array}$ & $\begin{array}{r}5.68 \\
-22.32\end{array}$ & $\begin{array}{r}5.68 \\
-24.32\end{array}$ & $\begin{array}{r}5.68 \\
-24.32\end{array}$ & $\begin{array}{r}5.68^{b} \\
-26.32\end{array}$ & 0.28 & 0.72 \\
\hline$\chi^{2}$ & $\begin{array}{r}12.82 \\
-15.18\end{array}$ & $\begin{array}{r}12.83 \\
-17.17\end{array}$ & $\begin{array}{r}13.05 \\
-16.95\end{array}$ & $\begin{array}{r}13.05^{b} \\
-18.95\end{array}$ & 0.52 & 0.49 \\
\hline $\begin{array}{l}\text { Alcoholism } \\
\chi^{2} \\
\text { AIC }\end{array}$ & $\begin{array}{r}6.03 \\
-21.97\end{array}$ & $\begin{array}{r}6.07 \\
-23.93\end{array}$ & $\begin{array}{r}6.03 \\
-23.97\end{array}$ & $\begin{array}{r}6.07^{b} \\
-25.93\end{array}$ & 0.61 & 0.39 \\
\hline
\end{tabular}


Table III. Reasons Given for Belief About Zygosity in Twin Pairs Where Both Correctly Felt They Were MZ, Both Mistakenly Felt They Were DZ When They Were Really MZ, and Both Correctly Felt They Were DZ

\begin{tabular}{|c|c|c|c|c|c|c|}
\hline \multirow{3}{*}{$\begin{array}{l}\text { Reason(s) for belief } \\
\text { about zygosity }\end{array}$} & \multicolumn{6}{|c|}{ True/perceived zygosity } \\
\hline & \multicolumn{2}{|c|}{$\begin{array}{c}\mathrm{MZ} / \mathrm{MZ} \\
(n=954)\end{array}$} & \multicolumn{2}{|c|}{$\begin{array}{c}\mathrm{MZ} / \mathrm{DZ} \\
(n=128)\end{array}$} & \multicolumn{2}{|c|}{$\begin{array}{c}\mathrm{DZ} / \mathrm{DZ} \\
(n=790)\end{array}$} \\
\hline & $n$ & $\%$ & $n$ & $\%$ & $n$ & $\%$ \\
\hline Physical appearance & 862 & $90.4^{* * *}$ & 56 & 43.8 & 745 & $94.3^{* * *}$ \\
\hline \multicolumn{7}{|l|}{ Parents told at birth } \\
\hline Total & 598 & $62.7^{* *}$ & 97 & 75.8 & 324 & $41.0 * * *$ \\
\hline \multicolumn{7}{|l|}{ Because of number of } \\
\hline placentas & 230 & $24.1 *$ & 44 & 34.4 & 126 & $15.9^{* * *}$ \\
\hline Told by Doctor & 165 & 17.3 & 20 & 15.6 & 80 & 10.1 \\
\hline Blood test & 63 & $6.6 * *$ & 1 & 0.8 & 13 & 1.6 \\
\hline Other & 208 & 21.8 & 22 & 17.2 & 122 & 15.4 \\
\hline
\end{tabular}

adds up to more than $100 \%$ because answers were not mutually exclusive.

${ }^{*} p<.05$, by $\chi^{2}, \mathrm{df}=1$, vs. pairs with true zygosity of $\mathrm{MZ}$ and perceived zygosity of $\mathrm{DZ}$.

${ }^{* *} p<.01$, by $\chi^{2}, \mathrm{df}=1$, vs. pairs with true zygosity of $\mathrm{MZ}$ and perceived zygosity of $\mathrm{DZ}$.

*** $p<.001$ by $\chi^{2}, \mathrm{df}=1$, vs. pairs with true zygosity of $\mathrm{MZ}$ and perceived zygosity of $\mathrm{DZ}$.

told at their birth. These results support the hypothesis that the asymmetry in mistaken zygosity beliefs in twins derives, in part, from mothers of dichorionic $\mathrm{MZ}$ twins being mistakenly told at birth, because of separate placentas, that their children were $\mathrm{DZ}$.

We applied structural equation modeling to five relatively common major psychiatric disorders in this sample, estimating separately the impact on twin similarity of "self-report" zygosity as a form of specified common environment. For all five disorders, model fitting provided no evidence for a significant effect of perceived zygosity on twin resemblance. More generally, these results suggest that the social and personal expectations associated with being considered an identical or fraternal twin pair have little effect on twin resemblance for common psychiatric disorders and are therefore unlikely to be major biases in twin studies of psychiatric illness. Our results are further supported by previous analyses which suggest that, when controlling for zygosity in the disorders examined, twin resemblance is generally unrelated to either childhood environmental similarity or frequency of adult contact (Kendler et al., 1991, 1992a-d).

The results of this report should be interpreted in the context of two potentially significant methodologic limitations. First, because of the relatively small number of twins whose perceived zygosity disagreed with their assigned zygosity, our statistical power to detect a phenotypic effect of perceived zygosity is modest. However, for four of the five disorders, the estimate of $c_{\mathrm{s}}{ }^{2}$ in the full model was zero or very close to zero, suggesting that the failure to find significant evidence for self-report zygosity may not be a result of small sample size. However, modest effects of self-report zygosity on twin resemblance for psychiatric disorders would probably go undetected in our analyses. Therefore, our results can most properly be considered as evidence against the hypothesis that a large proportion of the excess similarity of $\mathrm{MZ}$ over $\mathrm{DZ}$ twins for psychiatric disorders results from the expectation of greater resemblance in $\mathrm{MZ}$ twins by the twins themselves or their environment.

Second, only a limited number of our zygosity diagnoses were made using blood-group or DNA polymorphisms. With a twin sample this large, we were forced, for the sake of economy, to use an algorithm which obtained blood samples only in twin pairs where zygosity could not be confidently assigned after a review of traditional zygosity questions and personal photographs. Since our validation attempts for this method suggested that our error rate was very low, it is unlikely that the small number of errors made in zygosity assignment substantially biased our estimates of the impact of perceived zygosity on twin similarity. 


\section{ACKNOWLEDGEMENTS}

This work was supported by Grants $\mathrm{MH}-40828$ and AA-09095 from the United States National Institutes of Health. The Virginia Twin Registry, established and maintained by W. Nance M.D., Ph.D., and L. Corey, Ph.D., is supported by United States National Institutes of Health Grants HD-26746 and NS-25630. Leroy Thacker, M.S., assisted in the data analysis.

\section{REFERENCES}

Akaike, H. (1987). Factor analysis and AIC. Psychometrika 52:317-332.

American Psychiatric Association (1980). Diagnostic and Statistical Manual of Mental Disorders, 3rd ed., American Psychiatric Association, Washington, DC.

American Psychiatric Association (1987). Diagnostic and Statistical Manual of Mental Disorders, rev. 3rd ed., American Psychiatric Association, Washington, DC.

Clifford, C. A., Hopper, J. L., Fulker, D., and Murray, R. M. (1984). A genetic and environmental analysis of a twin family study of alcohol use, anxiety, and depression. Genet. Epidemiol. 1:63-79.

Goodman, R., and Stevenson, J. (1989). A twin study of hyperactivity. II. The aetiological role of genes, family relationships and perinatal adversity. J. Child. Psychol. Psychiat. 30:691-709.

Heath, A. C., Jardine, R., and Martin, N. G. (1989). Interactive effects of genotype and social environment on alcohol consumption in female twins. $J$. Stud. Alcohol 60:3848.

Kaprio, J., Koskenvuo, M., and Rose, R. J. (1990). Change in cohabitation and intrapair similarity of monozygotic (MZ) cotwins for alcohol use, extraversion, and neuroticism. Behav. Genet. 20:265-276.

Kendler, K. S. (1983). Overview: A current perspective on twin studies of schizophrenia. Am. J. Psychiat. 140:14131425.

Kendler, K. S., Heath, A. C., Martin, N. G., and Eaves, L. J. (1986). Symptoms of anxiety and depression in a volunteer twin population: The etiologic role of genetic and environmental factors. Arch. Gen. Psychiat. 43:213-221.

Kendler, K. S., MacLean, C. J., Neale, M. C., Kessler, R. C., Heath, A. C., and Eaves, L. J. (1991). The genetic epidemiology of bulimia nervosa. Am. J. Psychiat. 148:1627-1637.

Kendler, K. S., Neale, M. C., Kessler, R. C., Heath, A. C., and Eaves, L. J. (1992a). The genetic epidemiology of phobias in women: the inter-relationship of agoraphobia, social phobia, situational phobia and simple phobia. Arch. Gen. Psychiat. 49:273-281.

Kendler, K. S., Neale, M. C., Kessler, R. C., Heath, A. C., and Eaves, L. J. (1992b). Generalized anxiety disorder in women: a population based twin study. Arch. Gen. Psychiat. 49:267-272.
Kendler, K. S., Neale, M. C., Kessler, R. C., Heath, A. C., and Eaves, L. J. (1992c). A population based twin study of major depression in women: The impact of varying definitions of illness. Arch. Gen. Psychiat. 49:257-266.

Kendler, K. S., Heath, A. C., Neale, M. C., Kessler, R. C., and Eaves, L. J. (1992d). A population-based twin study of alcoholism in women $J A M A$ 268:1877-1882.

Loehlin, J. C., and Nichols, R. C. (1976). Heredity, Environment and Personality: A Study of 850 Sets of Twins, University of Texas Press, Austin.

Lykken, D. T., McGue, M., Bouchard, T. J., and Tellegen, A. (1990). Does contact lead to similarity or similarity to contact? Behav. Genet. 20:547-561.

Lytton, H. (1977). Do parents create, or respond to, differences in twins? Dev. Psychol. 13:456-459.

Martin, N. G., Eaves, L. J., Heath, A. C., Jardine, R., Feingold, L., and Eysenck, H. J. (1986). Transmission of social attitudes. Proc. Natl. Acad. Sci. 83:4364-4368.

Matheny, A. P., Jr. (1979). Appraisal of parental bias in twin studies: Ascribed zygosity and IQ differences in twins. Acta Genet. Med. Gemmellol. 28: 155-160.

Matheny, A.P., Jr., Wilson, R. S., and Dolan, A. B. (1976). Relations between twins' similarity of appearance and behavioral similarity: Testing an assumption. Behav. Genet. $6: 343-351$.

Morris-Yates, A., Andrews, G., Howie, P., and Henderson, S. (1990). Twins: A test of the equal environments assumption. Acta Psychiat. Scand. 81:322-326.

Munsinger, J., and Douglass, A., II (1976). The syntactic abilities of identical twins, fraternal twins, and their sib. lings. Child Dev. 47:40-50.

Neale, M. C. (1991). Statistical Modelling with Mx, Department of Human Genetics, Medical College of Virginia, Virginia Commonwealth University, Richmond.

Plomin, R., Willerman, L., and Loehlin, J. C. (1976). Resemblance in appearance and the equal environments assumption in twin studies of personality traits. Behav. Genet. $6: 43-52$.

Robins, L. N., and Helzer, J. E. (1985). Diagnostic Interview Schedule (DIS): Version III-A, Washington University School of Medicine, St. Louis, MO.

Rose, R. J., Kaprio, J., Williams, C. J., Viken, R., and Obremski, K. (1990). Social contact and sibling similarity: facts, issues, and red herrings. Behav. Genet. 20:763778.

Scarr, S. (1968). Environmental bias in twin studies. Eugen. Q. 15:34-40.

Scarr, S., and Carter-Saltzman, L. (1979). Twin method: Defense of a critical assumption. Behav. Genet. 9:527-542.

Spence, J. E., Corey, L. A., Nance, W. E., Marazita, M. L., Kendler, K. S., and Schieken, R. M. (1988). Molecular analysis of twin zygosity using VNTR DNA probes. Am. J. Hum. Genet. 43(3):A159.

Spitzer, R. L., Williams, J. B., and Gibson, M. (1987). Structured Clinical Interview for DSM-III-R, Biometrics Research Department, New York State Psychiatric Institute, New York. 